\title{
High microRNA-23a expression in laryngeal squamous cell carcinoma is associated with poor patient prognosis
}

\author{
Xiao-Wen Zhang ${ }^{1}$, Ning Liu', Sheng Chen ${ }^{1}$, Ye Wang ${ }^{1}$, Zhao-Xiong Zhang ${ }^{1}$, Yuan-Yuan Sun ${ }^{1}$, Guang-Bin Qiu ${ }^{2 *}$ \\ and Wei-Neng Fu ${ }^{1 *}$
}

\begin{abstract}
Background: MicroRNA-23a (miR-23a) has been demonstrated to play an important role in the development of several types of cancer, but its role in tumorigenesis of laryngeal carcinoma is still unclear. The aim of this study was to investigate the expression patterns and clinical implications of miR-23a in laryngeal cancer.

Methods: Quantitative RT-PCR was performed to evaluate the expression level of miR-23a in 52 pairs of laryngeal cancer. Analysis between miR-23a expression and clinical features of laryngeal carcinomas was performed by appropriate statistical methods. Role of miR-23a in laryngeal cancer cell migration and invasion was detected via transwell and matrigel assays, respectively.

Results: miR-23a was significantly up-regulated in laryngeal cancer tissues compared to normal adjacent laryngeal tissues $(P<0.01)$. Tumors with high miR-23a expression had significantly greater extent of lymph node metastasis $(P<0.01)$, worse clinical stage $(P<0.05)$ and shorter overall five-year survival $(P<0.01)$ than those with low miR-23a expression. Both univariate and multivariate Cox hazard regression analysis results showed that clinical stage and miR-23a expression were significantly correlated with patient five-year survival $(P<0.01)$. miR-23a overexpression also significantly promoted laryngeal cancer cell migration and invasion in vitro.
\end{abstract}

Conclusions: miR-23a, an independent prognostic factor for laryngeal cancer, participates in the onset and progression of laryngeal cancer.

Virtual slides: The virtual slide(s) for this article can be found here: http://www.diagnosticpathology.diagnomx.eu/vs/ 2021488014982305

Keywords: MicroRNA-23a, Laryngeal squamous cell carcinoma, Prognosis, Biomarker

\section{Background}

At present, the invasion and metastasis of tumor cells are considered as major causes of mortality in cancer patients [1]. According to the survey, the survival rate of laryngeal carcinoma patients with metastasis is only $30 \%-40 \%$ [2]. Although some tumor biomarkers such as carcinoembryonic antigen (CEA), carbohydrate antigen 19-9(CA19-9) are used to assess the possibility of

\footnotetext{
* Correspondence: qiuguangbin@163.com; wnfu@mail.cmu.edu.cn

${ }^{2}$ Department of Laboratory Medicine, No. 202 Hospital of PLA, No.5,

Guangrong Street, Heping district, Shenyang, Liaoning Province 110003, P. R.

China

'Department of Medical Genetics, China Medical University, No.77 Puhe Road, Shenyang North New Area, Shenyang, Liaoning Province 110122, P R
} China

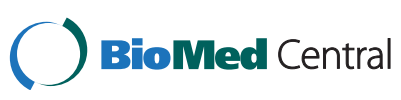

(c) 2015 Zhang et al.; licensee BioMed Central. This is an Open Access article distributed under the terms of the Creative Commons Attribution License (http://creativecommons.org/licenses/by/4.0), which permits unrestricted use, distribution, and reproduction in any medium, provided the original work is properly credited. The Creative Commons Public Domain Dedication waiver (http://creativecommons.org/publicdomain/zero/1.0/) applies to the data made available in this article unless otherwise stated. tumors metastasis [3], there is still lack of ideal biomarkers for predicting invasion and metastasis of cancer patients.

MicroRNAs (miRNAs) are a category of small (19 24 nucleotides), non-coding and single-stranded endogenous RNA molecules that influence multiple biological events, especially the development and progress of malignancies [4-7]. Some studies have reported that miRNA could be used as a biomarker for the invasion and metastasis of several types of cancer [8-12]. However, the expression patterns and role of miRNAs in laryngeal carcinoma are seldom reported in the literature.

MiR-23a is aberrantly expressed in many cancers such as breast cancer, colorectal cancer, lung cancer, gastric 
cancer and glioma, and plays important roles in regulation of apoptosis and proliferation [13-18]. Similar to our recent work, miR-23a promotes proliferation and represses apoptosis in laryngeal squamou cell cancer (LSCC) (unpublished observations) and pancreatic cancer through directly targeting the APAF-1 3'UTR [19]. Also, miR-23a has been demonstrated to participate in regulation of invasion and metastasis in some cancers such as colorectal carcinoma and neuroblastoma $[15,20]$. Li et al. discovered a series of differentially expressed miRNAs including miRNA-23a in formalin-fixed paraffin-embedded laryngeal carcinoma tissues and the paired normal controls based on the miRNA microarray and found that miRNA-23a is associated with the lymphatic metastasis of laryngeal carcinoma [21]. However, the role of miR-23a in invasion and metastasis of laryngeal carcinoma is still unclear.

In the study, the miR-23a gene expression in laryngeal carcinoma tissues was detected by Quantitative RT-PCR. Correlations of miR-23a to survival and clinic-pathological features of LSCC patients were analyzed. Prognostic factors related to LSCC were revealed by univariate and multivariate analysis. Role of miR-23a in invasion and metastasis of Hep-2 (human laryngeal cancer) cells was also evaluated by matrigel and transwell assays, respectively.

\section{Methods}

\section{Patients and tissue samples}

This study was approved by the Research Ethics Committee of China Medical University (Shenyang, China) and the 463th Hospital of PLA (Shenyang, China). Written informed consent was obtained from all patients. All specimens were handled and made anonymous according to the ethical and legal standards.

Fifty-two pairs of laryngeal carcinoma tissue and paired adjacent normal tissue were obtained from each patient who underwent surgical resection treatment at the 463th Hospital of PLA (Shenyang, China) between 1999 and 2011, and were subsequently diagnosed based on histopathological evaluation. Normal laryngeal mucosa specimens were retrieved $10 \mathrm{~mm}$ outside the negative margin. Samples were placed in RNAlater Tissue Protect Tubes (Qiagen, Hilden, Germany) and stored at $-80^{\circ} \mathrm{C}$. Postsurgical pathology confirmed the diagnosis of squamous cell carcinoma in all patients. All patients did not receive radio- or chemotherapy before surgery.

\section{Cell culture and transfection}

Hep-2 cell lines obtained from the Cell Biology Institute of Shanghai, Chinese Academy of Science were maintained in RPMI 1640 (GIBCO, Los Angeles, CA) medium supplemented with $10 \%$ fetal bovine serum (Hyclone, Logan, USA), 100 units $/ \mathrm{ml}$ penicillin and $100 \mu \mathrm{g} / \mathrm{ml}$ streptomycin in a humidified atmosphere at $37^{\circ} \mathrm{C}$ with $5 \% \mathrm{CO}_{2}$.
For transfection assay, Hep-2 cells were transfected with miR-23a inhibitor, inhibitor negative control, miR23a mimic and miR-23a mimic negative control, respectively, by using Lipofectamine ${ }^{\mathrm{tw}} 2000$ reagent (Invitrogen, Carlsbad, CA) according to the manufacturer's instructions. All the nucleotide sequences used in the study are shown in Table 1.

\section{RNA extraction, reverse transcription and quantitative RT-PCR}

Total RNA was extracted from the corresponding tissues using a miRcute miRNA isolation kit (Tiangen, Bejing, China) according to the manufacturer's instructions. Reverse transcription was performed using the One Step Prime Script miRNA cDNA Synthesis Kit (Takara, Dalian, China) following the manufacturer's instructions.

Quantitative RT-PCR was performed using SYBR ${ }^{\circ}$ Premix Ex Taq ${ }^{\mathrm{mm}}$ II (Takara, Dalian, China) according to the manufacturer's instructions with the 7500 real-time RTPCR system (Applied Biosystems, Foster City). U6B was used as the normalization control. Each detection was performed in triplicate.

\section{Migration and invasion assays}

Hep-2 Cells were suspended in serum-free medium. For migration and invasion assays, non-coated and Matrigelcoated membranes (24-well insert; $8-\mu \mathrm{m}$ pore size; Corning Costar Corp) were used, respectively. The Matrigel-coated membrane was prepared with $30 \mu \mathrm{l}$ Matrigel (BD Biosciences, San Jose, CA) and incubated for $40 \mathrm{~min}$ at $37^{\circ} \mathrm{C}$ in advance. In details, $1 \times 10^{5}$ cells were plated in the top chamber with the non-coated and Matrigel-coated membranes, respectively. Medium supplemented with serum was used as a chemoattractant in

\section{Table 1 The nucleotide sequences used in the study}

\begin{tabular}{ll}
\hline Name & Sequence \\
\hline miR-23a mimics & 5'-AUCACAUUGCCAGGGAUUUCC-3' \\
miR-23a inhibitor & 5'-GGAAAUCCCUGGCAAUGUGAU-3' \\
mimics NC & 5'-UUCUCCGAACGUGUCACGUTT-3' \\
inhibitor NC & 5'-CAGUACUUUUGUGUAGUACAA-3' \\
NC & 5'-GGCUACGUCCAGGAGCGCA CC-3' \\
miRNA-23a (reverse & 5'-CTCAACTGGTGTCGTGGAGTCGG \\
transcription primer) & CAATTCAGTGAGGGAATCC-3' \\
miRNA-23a F & 5'-ACACTCCAGCTGGGATCACATTGCCAGGGATTT-3' \\
miRNA-23a R & 5'-TGGTGTCGTGGAGTCG-3' \\
U6F & 5'-CTCGCTTCGGCAGCACA-3' \\
U6R & 5'-AACGCTTCACGAATTTGCGT-3' \\
GAPDHF & 5'-ATCATCAGCAATGCCTCC-3' \\
GAPDHR & 5'-CATCACGCCACAGTTCC-3' \\
\hline
\end{tabular}

Note: $\mathrm{F}$ and $\mathrm{R}$ indicates forward and reverse primers, respectively. NC shows the negative control. 


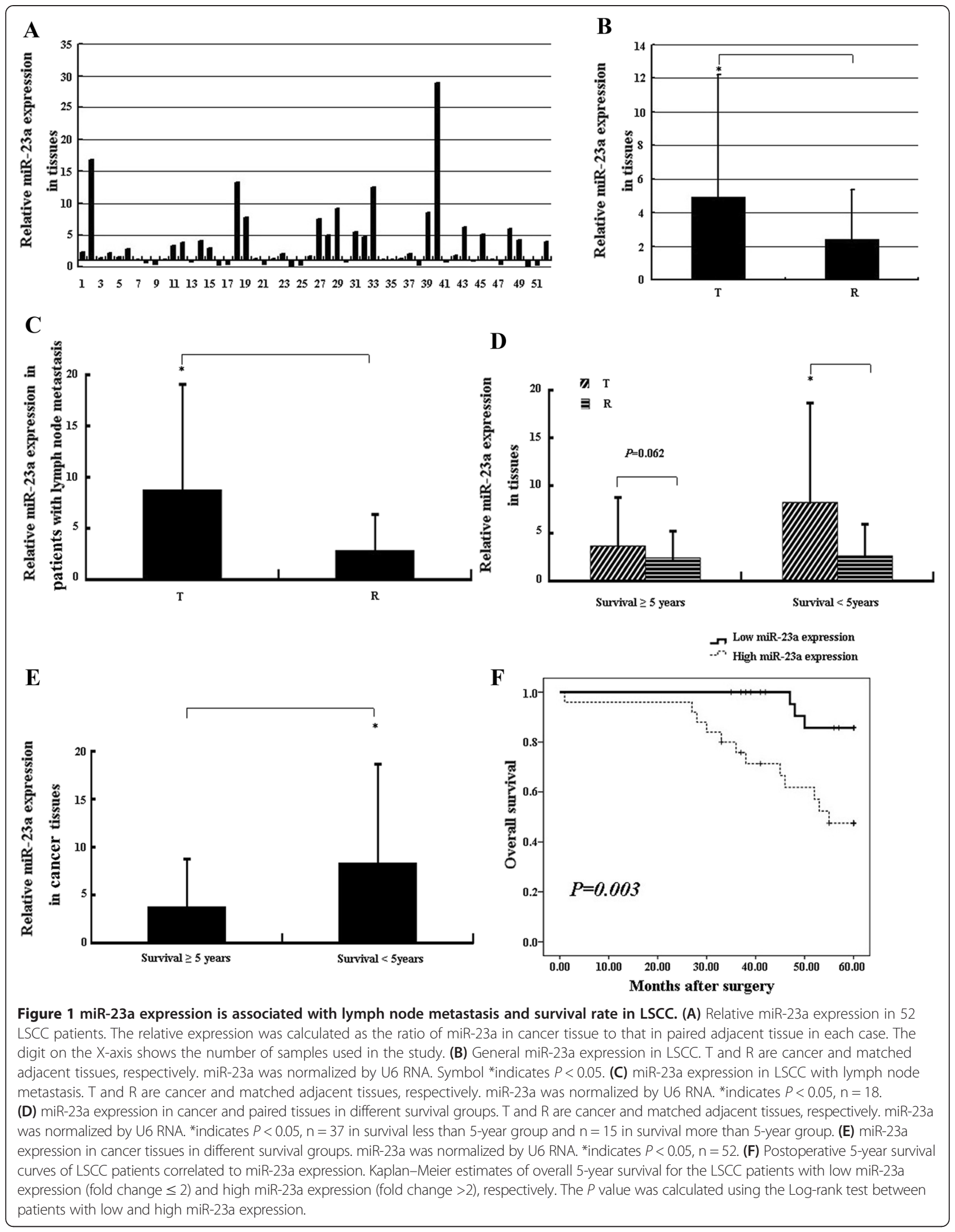


Table 2 Association between miR-23a and clinicopathological characteristics in $\mathbf{5 2}$ patients with LSCC

\begin{tabular}{|c|c|c|c|}
\hline Features & No.of cases & miR-23a expression & $P$-value \\
\hline \multicolumn{4}{|l|}{ Age } \\
\hline$<60$ & 22 & $3.87 \pm 4.50$ & 0.234 \\
\hline$\geq 60$ & 30 & $6.35 \pm 10.00$ & \\
\hline \multicolumn{4}{|l|}{ Gender } \\
\hline male & 45 & $5.17 \pm 7.85$ & 0.543 \\
\hline female & 7 & $3.32 \pm 2.27$ & \\
\hline \multicolumn{4}{|l|}{ Smoking } \\
\hline Nonsmokers & 7 & $3.48 \pm 5.36$ & 0.584 \\
\hline Current smokers & 45 & $5.14 \pm 7.65$ & \\
\hline \multicolumn{4}{|l|}{ Drinking } \\
\hline drinker & 37 & $5.54 \pm 8.31$ & 0.346 \\
\hline nondrinker & 15 & $3.39 \pm 4.08$ & \\
\hline \multicolumn{4}{|l|}{ Differentiation } \\
\hline well & 15 & $3.06 \pm 2.25$ & 0.251 \\
\hline Moderate & 29 & $4.91 \pm 8.43$ & \\
\hline Poor & 8 & $8.46 \pm 8.88$ & \\
\hline \multicolumn{4}{|l|}{ Lymph node } \\
\hline Negative & 34 & $2.93 \pm 3.72$ & $0.006^{*}$ \\
\hline Positive & 18 & $8.67 \pm 10.63$ & \\
\hline \multicolumn{4}{|l|}{ Tumor depth (pT) } \\
\hline $\mathrm{T} 1$ & 9 & $2.52 \pm 2.17$ & 0.226 \\
\hline $\mathrm{T} 2$ & 15 & $3.37 \pm 5.95$ & \\
\hline T3 & 15 & $4.97 \pm 5.77$ & \\
\hline $\mathrm{T} 4$ & 13 & $8.31 \pm 11.29$ & \\
\hline \multicolumn{4}{|l|}{ Clinical stage } \\
\hline । & 6 & $2.04 \pm 1.67$ & $0.011^{*}$ \\
\hline$\|$ & 12 & $1.88 \pm 1.67$ & \\
\hline III & 31 & $5.54 \pm 6.6$ & \\
\hline IV & 3 & $16.44 \pm 20.48$ & \\
\hline
\end{tabular}

One-way ANOVO was used to analyze the correlation between the expression of miR-23a and clinicopathological features of the patients. *indicates $P<0.05$.

the lower chamber. Cells were incubated for 24 hours at $37^{\circ} \mathrm{C}$ in a $5 \% \mathrm{CO}_{2}$ incubator and those that did not migrate or invade through the pores were removed by a cotton swab. Cells on the lower surface of the membrane were then fixed with methanol, stained with hematoxylin and eosin, and subjected to microscopic inspection and photographed. Values for migration and invasion were obtained by counting five fields per membrane and each experiment was performed at least three times.

\section{Statistical analysis}

SPSS16.0 software for Windows (SPSS Inc, IL, USA) was used for statistical analysis. Data were expressed as the mean \pm standard deviation (SD). The differential expression of miR-23a between laryngeal cancer and the matched adjacent mucosa was evaluated by paired sample t-test. $X^{2}$ test was used to analyze association of miR23a with survival. One-way ANOVO was applied to evaluate the relationship between miR-23a expression and the clinic-pathologic characteristics. Kaplan-Meier method was used for survival analysis. Difference in survival was estimated using the log-rank test. Risk factors for LSCC were examined by univariate and multivariate analyses (Cox proportional hazards regression model). $P<0.05$ was considered statistically significant.

\section{Results}

Increased miR-23a expression participates in laryngeal carcinogenesis

miR-23a expression was detected in 52 pairs of laryngeal cancer tissue and the matched adjacent tissue by qRTPCR. As showed in Figure 1A, miR-23a level was increased in 37 out of 52 (71.2\%) laryngeal cancer tissues

Table 3 Univariate and multivariate Cox hazard regression analysis for prognostic factors

\begin{tabular}{|c|c|c|c|}
\hline & \multicolumn{2}{|l|}{ Univariate analysis } & \multirow{2}{*}{$\begin{array}{l}\text { Multivariate analysis } \\
\text { Hazard ratio } \\
\text { ( } 95 \% \text { confidence } \\
\text { interval) }\end{array}$} \\
\hline & $\begin{array}{l}\text { Hazard ratio } \\
\text { (95\% confidence } \\
\text { interval) }\end{array}$ & $P$ value & \\
\hline \multicolumn{4}{|l|}{ Gender } \\
\hline Male vs female & $1.349(0.458-3.973)$ & 0.587 & \\
\hline \multicolumn{4}{|l|}{ Age } \\
\hline$\geq 60$ vs $<60$ & $1.849(0.760-4.498)$ & 0.176 & \\
\hline \multicolumn{4}{|l|}{ Smoking } \\
\hline $\begin{array}{l}\text { Smoker vs } \\
\text { Nonsmoker }\end{array}$ & $0.848(0.250-2.868)$ & 0.790 & \\
\hline \multicolumn{4}{|l|}{ Drinking } \\
\hline $\begin{array}{l}\text { Drinker vs } \\
\text { nondrinker }\end{array}$ & $0.818(0.345-1.942)$ & 0.649 & \\
\hline \multicolumn{4}{|l|}{ Differentiation } \\
\hline $\begin{array}{l}\text { Poor vs } \\
\text { moderate } \\
\text { vs well }\end{array}$ & $0.762(0.415-1.399)$ & 0.381 & \\
\hline \multicolumn{4}{|l|}{$\begin{array}{l}\text { Tumor } \\
\text { depth (PT) }\end{array}$} \\
\hline $\begin{array}{l}\text { T4vs T3 vs } \\
\text { T2 vs T1 }\end{array}$ & $2.173(1.380-3.422)$ & $0.001^{*}$ & \\
\hline \multicolumn{4}{|l|}{$\begin{array}{l}\text { Lymph node } \\
\text { metastasis }\end{array}$} \\
\hline $\begin{array}{l}\text { Positive vs } \\
\text { negative }\end{array}$ & $4.243(1.844-9.764)$ & $0.001^{*}$ & \\
\hline \multicolumn{4}{|l|}{ Clinical stage } \\
\hline IVvs IIIvs IIvs| & $5.513(2.300-13.214)$ & $P<0.001^{*}$ & $6.998(2.217-22.083)$ \\
\hline \multicolumn{4}{|l|}{$\begin{array}{l}\text { miR-23a } \\
\text { expression }\end{array}$} \\
\hline High vs low & $7.419(2.561-21.491)$ & $P<0.001^{*}$ & $6.712(2.076-21.700)$ \\
\hline
\end{tabular}

*indicates $P<0.05$. 
compared to the controls. In general, miR-23a was significantly up-regulated in laryngeal cancer tissues compared with normal counterpart $(P<0.05)$ (Figure $1 \mathrm{~B})$, suggesting that miR-23a takes part in the genesis of laryngeal cancer.

\section{High miR-23a level contributes to poor prognosis in patients with laryngeal carcinomas}

In 18 cases of patients with lymph nodes metastasis, miR-23a was significantly up-regulated in laryngeal cancer tissues compared to the normal counterpart $(P<$ 0.05) (Figure 1C; Table 2). In patients aged less than 5 years after operation, miR-23a expression level was significantly higher in cancer tissues than that in controls $(P<0.05)$ (Figure 1D). miR-23a average level in cancer tissues was at higher level in patients aged less than 5 years, which showed a significant difference compared to that in patients aged more than 5 years $(P<0.05)$ (Figure 1E). These results imply that miR-23a expression level correlates with lymph nodes metastasis and patients' survival in laryngeal cancer.

To better understand the potential roles of miR-23a in LSCC development and progression, one-way ANOVO was used to determine the relationships of miR-23a with various clinical features of LSCC, including age, gender, smoking, drinking, lymph nodes metastasis, differentiation, and clinic-pathological stage. As shown in Table 2, miR-23a overexpression in tumor tissues was strongly associated with lymph node metastasis and advanced clinical stage of LSCC ( $P=0.006$ and $P=0.011$, respectively).

We then used Kaplan-Meier method, log-rank test and Cox proportional hazard regression model to analyze the survival correlation of LSCC patients with miR-23a expression and clinic-pathological features. Up-regulated

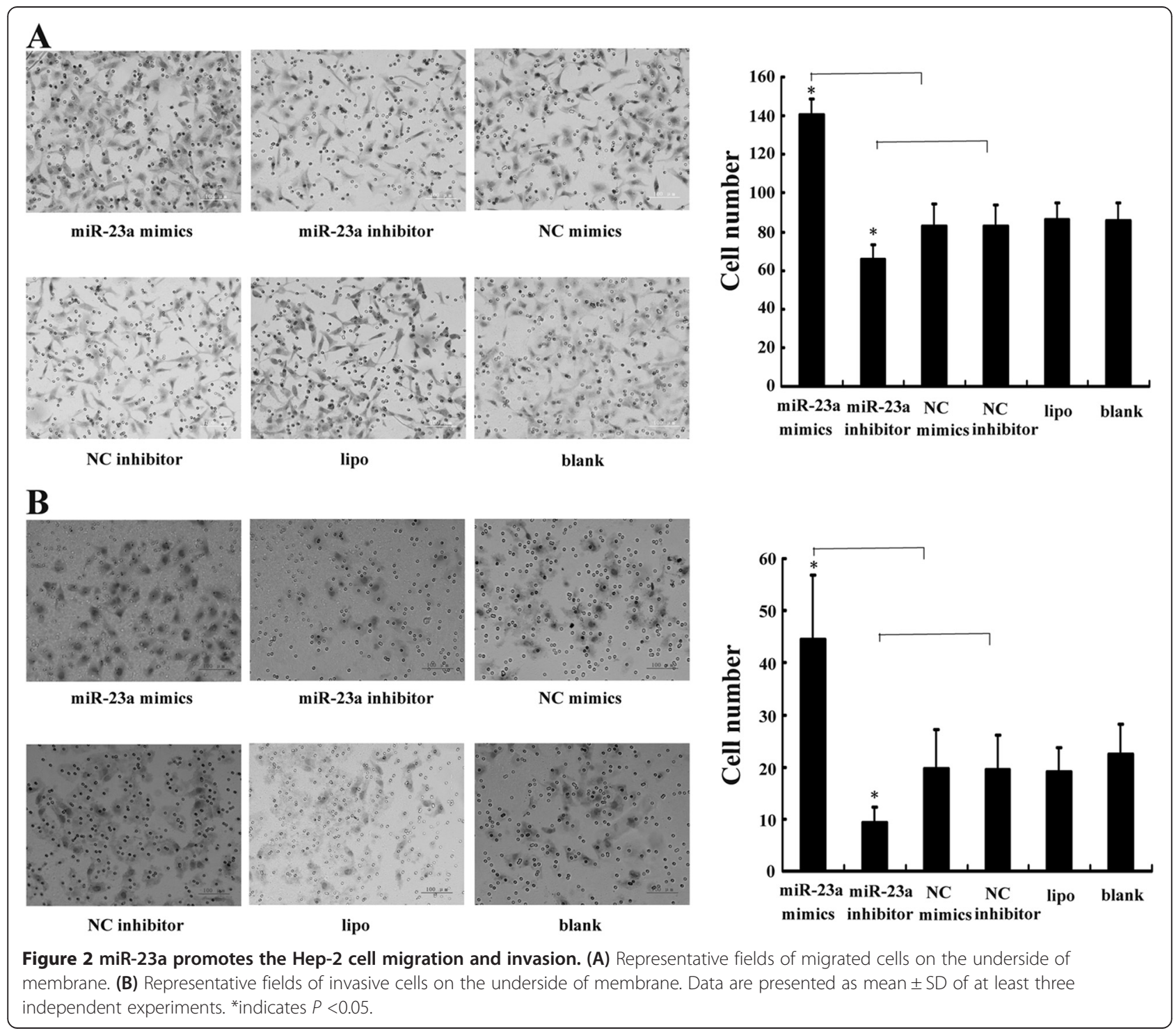


more than 2-fold is considered to be high miR-23a expression. As indicated in Figure 1F, high miR-23a level was correlated with shorter overall five-year survival of LSCC patients (log-rank test: $P=0.003)$. Univariate Cox hazard regression analysis results showed that LSCC patient survival was significantly correlated with tumor depth, lymph node metastasis, clinical stage and miR-23a expression. However, only clinical stage and miR-23a expression were significantly correlated with patient survival after multivariate analysis was performed (Table 3).

\section{miR-23a promotes cell migration and invasion in laryngeal cancer Hep-2 cells}

To confirm the role of miR-23ain laryngeal cancer metastasis, we examined the effect of miR-23aon laryngeal cancer cell migration and invasion in vitro. As results, both migrated and invaded cells significantly increased and decreased in miR-23a mimic and miR-23a inhibitor groups compared to the controls, respectively, implying that miR-23a promotes laryngeal cancer cell migration and invasion (Figure 2).

\section{Discussion}

Several genes, such as P53, HER2 and Bcl-2, are considered to be tissue biomarkers for the early diagnosis of malignant tumor or assessing the prognosis of patients with tumor $[22,23]$. However, their clinical utility is limited due to their inexistence in body fluids. It is surprising that miRNAs are easily detected by qRT-PCR $[24,25]$. Moreover, miRNAs are found stable in 12 different biological fluids such as plasma, saliva, tears, urine, amniotic fluid, colostrum, breast milk, bronchial secretions, cerebrospinal fluid, peritoneal fluid, pleural fluid and seminal fluid [26]. Furthermore, these circulating miRNAs from different fluids especially from serum and urine can reflect the state of a given disease, suggesting that they are useful biomarkers in a broad range of clinical applications in human diseases [27].

In the study, we found miR-23a was significantly upregulated in laryngeal carcinoma tissues compared to the adjacent tissues, which is consistent with previous findings in most solid tumors such as colon carcinoma, lung cancer and neuroblastoma, respectively $[15,16,20]$. In contrast, miR-23a is found to be down-regulated in chronic or acute leukemia $[10,28]$, respectively. Nevertheless, the abnormal miR-23a expression plays a critical role in carcinogenesis.

In addition, we found that the miR-23a gene expression in laryngeal carcinoma patients with lymph node metastasis is significantly higher than that in patients without lymph node metastasis. The result is consistent with previous report [21]. Our results also indicated that high level of miR-23a correlates with LSCC clinical stages, suggesting that miR-23a participates in laryngeal cancer cell migration and invasion, which is confirmed in vitro in the study. These results are in line with previous findings in colorectal cancer and neuroblastoma [15-20].

The overall five-year survival of laryngeal cancer patients has not improved (at approximately 35-70\%). Conversely, it decreases in the United state $[29,30]$. Therefore, there is a great need to identify new biomarkers for the diagnosis and prognosis of laryngeal carcinoma. Our present study demonstrated that high miR-23a level in laryngeal cancer tissues significantly correlates with poorer five-year survival, which is reconfirmed by our multivariate Cox hazard regression analysis, implying that miR-23a expression level is an independent prognostic factor for laryngeal cancer in addition to clinical stage. Similar result is also found in liver cancer [31]. In addition to miR-23a, we also found that clinical stage is also related to poor progression in LSCC.

In the future, our work will focus on the molecular mechanism of miR-23a in laryngeal cancer cell migration and invasion.

\section{Conclusion}

miR-23a is an independent prognostic factor for laryngeal cancer and participates in the onset and progression of laryngeal cancer.

\section{Abbreviations}

LSCC: Laryngeal squamou cell cancer; miRNA: microRNA; UTR: Untranslation region.

\section{Competing interests}

The authors declare that they have no competing interests.

\section{Authors' contributions}

XW carried out qRT-PCR and participated in the statistical analysis and drafted the manuscript. N carried out migration detection. S carried out invasion assay. $Y$ and $Z X$ participated in QRT-PCR assays. YY participated in migration and invation assays. GB participated in the design of the study and the statistical analysis. WN participated in the design of the study and revised the manuscript. All authors read and approved the final manuscript.

\section{Authors' information}

$X W, N, S, Y, Z X$ and $Y Y$ are post-graduate students. GB is a director of Laboratory Medicine Department, No. 202 Hospital of PLA. WN is an associate director of Medical Genetics Department of China Medical University.

\section{Acknowledgements}

This work was supported by the National Natural Science Foundation of China (81172577 and 81372876). We thank professor Bao-Shen Zhou (Department of Epidemiology, China medical University) to give us an advice on statistical analysis.

Received: 14 November 2014 Accepted: 25 March 2015

Published online: 03 April 2015

\section{References}

1. Jemal A, Bray F, Center MM, Ferlay J, Ward E, Forman D. Global cancer statistics. CA Cancer J Clin. 2011;61:69-90.

2. Gourin CG, Conger BT, Sheils WC, Bilodeau PA, Coleman TA, Porubsky ES. The effect of treatment on survival in patients with advanced laryngeal carcinoma. Laryngoscope. 2009;119:1312-7.

3. Shibutani M, Maeda K, Nagahara H, Ohtani H, Sakurai K, Toyokawa T, et al. Significance of CEA and CA19-9 combination as a prognostic indicator and for recurrence monitoring in patients with stage II colorectal cancer. Anticancer Res. 2014;34:3753-8. 
4. Lages $E$, Ipas H, Guttin A, Nesr H, Berger F, Issartel JP. MicroRNAs: molecular features and role in cancer. Front Biosci (Landmark Ed). 2012;17:2508-40.

5. Doench JG, Sharp PA. Specificity of microRNA target selection in translational repression. Genes Dev. 2004;18:504-11.

6. Croce CM, Calin GA. miRNAs, cancer, and stem cell division. Cell. 2005;122:6-7.

7. Ambros $V$. The functions of animal microRNAs. Nature. 2004:431:350-5.

8. Sun X, Liu Z, Yang Z, Xiao L, Wang F, He Y, et al. Association of microRNA-126 expression with clinicopathological features and the risk of biochemica recurrence in prostate cancer patients undergoing radical prostatectomy. Diagn Pathol. 2013;8:208.

9. Su ZX, Zhao J, Rong ZH, Geng WM, Wu YG, Qin CK. Upregulation of microRNA-25 associates with prognosis in hepatocellular carcinoma. Diagn Pathol. 2014;9:47.

10. Zhu X, Lin Z, Du J, Zhou X, Yang L, Liu G. Studies on microRNAs that are correlated with the cancer stem cells in chronic myeloid leukemia. Mol Cell Biochem. 2014;390:75-84.

11. Han ZB, Chen HY, Fan JW, Wu JY, Tang HM, Peng ZH. Up-regulation of microRNA-155 promotes cancer cell invasion and predicts poor survival of hepatocellular carcinoma following liver transplantation. J Cancer Res Clin Oncol. 2012;138:153-61.

12. $Y u$ J, Wang $Y$, Dong $R$, Huang $X$, Ding S, Qiu H. Circulating microRNA-218 was reduced in cervical cancer and correlated with tumor invasion. J Cancer Res Clin Oncol. 2012;138:671-4.

13. Li X, Liu X, Xu W, Zhou P, Gao P, Jiang S, et al. c-MYC-regulated miR-23a/24-2/ 27a cluster promotes mammary carcinoma cell invasion and hepatic metastasis by targeting Sprouty2. J Biol Chem. 2013;288:18121-33.

14. Yong FL, Wang CW, Roslani AC, Law CW. The involvement of miR-23a/ APAF1 regulation axis in colorectal cancer. Int J Mol Sci. 2014;15:11713-29.

15. Jahid S, Sun J, Edwards RA, Dizon D, Panarelli NC, Milsom JW, et al. miR-23a promotes the transition from indolent to invasive colorectal cancer. Cancer Discov. 2012;2:540-53.

16. Cao M, Li Y, Lu H, Meng Q, Wang L, Cai L, et al. miR-23a-mediated migration/invasion is rescued by its target, IRS-1, in non-small cell lung cancer cells. J Cancer Res Clin Oncol. 2014;140:1661-70.

17. Liu X, Liu Q, Fan Y, Wang S, Liu X, Zhu L, et al. Downregulation of PPP2R5E expression by miR-23a suppresses apoptosis to facilitate the growth of gastric cancer cells. FEBS Lett. 2014;588:3160-9.

18. Lian S, Shi R, Bai T, Liu Y, Miao W, Wang H, et al. Anti-miRNA-23a oligonucleotide suppresses glioma cells growth by targeting apoptotic protease activating factor-1. Curr Pharm Des. 2013;19:6382-9.

19. Liu N, Sun $Y Y$, Zhang XW, Chen S, Wang Y, Zhang ZX, et al. Oncogenic miR-23a in Pancreatic Ductal Adenocarcinogenesis Via Inhibiting APAF1. Dig Dis Sci. 2015 Feb 21, Online.

20. Cheng L, Yang T, Kuang Y, Kong B, Yu S, Shu H, et al. MicroRNA-23a promotes neuroblastoma cell metastasis by targeting $\mathrm{CDH} 1$. Oncol Let. 2014; $7: 839-45$

21. Li L, Zhang ZM, Liu Y, Wei MH, Xue LY, Zou SM, et al. DNA microarrays-based microRNA expression profiles derived from formalin-fixed paraffin-embedded tissue blocks of squammous cell carcinoma of larynx. Zhonghua Bing Li Xue Za Zhi. 2010;39:391-5

22. Nishimura R, Osako T, Okumura $Y$, Tashima R, Toyozumi $Y$, Arima N. Changes in the ER, PgR, HER2, p53 and Ki-67 biological markers between primary and recurrent breast cancer: discordance rates and prognosis. World J Surg Oncol. 2011;9:131.

23. Zhao L, Yu N, Guo T, Hou Y, Zeng Z, Yang X, et al. Tissue biomarkers for prognosis of prostate cancer: a systematic review and meta-analysis. Cancer Epidemiol Biomarkers Prev. 2014;23:1047-54.

24. Grasedieck S, Sorrentino A, Langer C, Buske C, Döhner H, Mertens D, et al. Circulating microRNAs in hematological diseases: principles, challenges, and perspectives. Blood. 2013;121:4977-84.

25. Allegra A, Alonci A, Campo S, Penna G, Petrungaro A, Gerace D, et al. Circulating microRNAs: new biomarkers in diagnosis, prognosis and treatment of cancer. Int J Oncol. 2012;41:1897-912.

26. Weber JA, Baxter DH, Zhang S, Huang DY, Huang KH, Lee MJ, et al. The microRNA spectrum in 12 body fluids. Clin Chem. 2010;56:1733-41.

27. De Guire V, Robitaille R, Tétreault N, Guérin R, Ménard C, Bambace N, et al. Circulating miRNAs as sensitive and specific biomarkers for the diagnosis and monitoring of human diseases: promises and challenges. Clin Biochem. 2013;46:846-60.
28. Scheibner KA, Teaboldt B, Hauer MC, Chen X, Cherukuri S, Guo Y, et al. MiR-27a functions as a tumor suppressor in acute leukemia by regulating 14-3-30. PLoS One. 2012;7:e50895.

29. Chin D, Boyle GM, Porceddu S, Theile DR, Parsons PG, Coman WB. Head and neck cancer: past, present and future. Expert Rev Anticancer Ther. 2006;6:1111-8.

30. Hoffman HT, Porter K, Karnell LH, Cooper JS, Weber RS, Langer CJ, et al. Laryngeal cancer in the United States: changes in demographics, patterns of care, and survival. Laryngoscope. 2006;116 Suppl 111:1-13.

31. Bao L, Zhao J, Dai X, Wang Y, Ma R, Su Y, et al. Correlation between miR-23a and onset of hepatocellular carcinoma. Clin Res Hepatol Gastroenterol. 2014;38:318-30.

\section{Submit your next manuscript to BioMed Central and take full advantage of:}

- Convenient online submission

- Thorough peer review

- No space constraints or color figure charges

- Immediate publication on acceptance

- Inclusion in PubMed, CAS, Scopus and Google Scholar

- Research which is freely available for redistribution 